\title{
PENGARUH BRAND EQUITY DAN CONSUMER SATISFACTION PADA BRAND LOYALTY
}

\author{
A.A Gede Tresna SP $^{1}$ \\ Ni Ketut Seminari ${ }^{2}$ \\ ${ }^{1,2}$ Fakultas Ekonomi dan Bisnis Universitas Udayana (Unud), Bali, Indonesia \\ email: gungpecut@gmail.com
}

\begin{abstract}
ABSTRAK
Meningkatnya budaya niat beli masyarakat seiring dengan meningkatknya loyalitas terhadap suatu merk produk. Makalah ini bertujuan untuk menganalisis pengaruh brand equity dan customer satisfaction pada brand loyalty produk Nevada di Kota Denpasar. Studi dilakukan dilakukan di Kota Denpasar dengan ukuran sampel sebanyak 140 responden menggunakan metode purposive sampling. Hasil analisis menemukan brand equity berpengaruh positif signifikan terhadap brand loyalty. Customer satisfaction berpengaruh positif signifikan terhadap brand loyalty. Saran yang dapat direkomendasikan bagi produsen produk merk Nevada harus memperhatikan posisi suatu merk yang sesuai dengan pandangan konsumen seperti menjaga kualitas produk, harga produk sehingga mampu meningkatkan loyalitas konsumen. Nevada harus mempertahankan kualitas layanan yang diberikan selama ini kepada konsumen, karena kualitas pelayanan sebagai kunci yang sangat menentukan customer satisfaction sehingga meningkatkan loyalitas konsumen untuk membeli produk Nevada di Kota Denpasar.
\end{abstract}

Kata kunci : brand equity, customer satisfaction, brand loyalty

\begin{abstract}
Increased cultural intention to buy the community along with increasing loyalty to a product brand. This paper aims to analyze the influence of brand equity and customer satisfaction on Nevada brand loyalty products in Denpasar City. The study was conducted in Denpasar with sample size of 140 respondents using purposive sampling method. The results of the analysis found that brand equity has a significant positive effect on brand loyalty. Customer satisfaction has a significant positive effect on brand loyalty. Suggestions that can be recommended for manufacturers of Nevada brand products should consider the position of a brand in accordance with consumer views such as maintaining product quality, product prices so as to increase consumer loyalty. Nevada must maintain the quality of service provided so far to consumers, because the quality of service as a key that determines customer satisfaction so as to increase customer loyalty to buy products Nevada in Denpasar.
\end{abstract}

Keywords: brand equity, customer satisfaction, brand loyalty 
A.A. Gede Tresna SP, Pengaruh Brand Equity Dan...

\section{PENDAHULUAN}

Kondisi persaingan yang semakin ketat dengan adanya tuntutan konsumen yang semakin besar membuat tugas seorang pemasar menjadi semakin sulit dan kompleks, mereka tidak hanya menginginkan produk yang berkualitas dengan harga yang murah, namun saat ini mereka juga menginginkan produk yang bisa meningkatkan kepuasannya (Ali et al., 2013). Terlebih lagi dalam hal pemenuhan terhadap kebutuhan, konsumen sekarang ini cenderung lebih individualis dan menuntut sesuatu hal yang lebih bersifat pribadi atau personal. Untuk memenuhi kebutuhan tersebut perusahaan dituntut mampu memahami keinginan dan kebutuhan konsumen agar tetap survive (Rangkas dan Syahputra, 2014). Diterima atau tidaknya produk yang dijual saat ini oleh konsumen, tidak tergantung pada produk tersebut saja, melainkan terkait dengan komunikasi pemasaran yang diberikan serta brand equity pada produk tersebut.

Pada tahun 2016 ini, industri fashion di Indonesia dirasakan berkembang dengan semakin cepat dan menjadi fokus perhatian masyarakat, hal ini dibuktikan dapat kita lihat dari semakin banyaknya pusat perbelanjaan di Indonesia dan kotakota besar seperti Bali yang tidak kalah hebat dengan pusat perbelanjaan kelas Dunia (Ravie, 2012). Pusat perbelanjaan tersebut selalu saja dipenuhi oleh pengunjung, hal ini dilihat oleh sebagian pengamat Ekonomi sebagai potensi daya beli masyarakat yang besar (Herry, 2011).

Produk Nevada collection yang sampai saat ini menawarkan rancangan bergaya casual dan menarik bergaya modern mengikuti perkembangan mode yang khusus didesain untuk kalangan-kalangan muda, remaja dan dewasa. Produk 
Nevada collection mudah ditemukan di hampir seluruh pusat perbelanjaan dan plasa di Indonesia khususnya Bali. Untuk produk fashion Nevada sendiri, antara lain berupa kaos, sweater, jaket, baju anak, rok, dan aneka produk fashion lainnya. Selain itu, selebritis lokal seperti Geremy Thomas, Chelsea Islan, Ariel dan tidak ketinggalan bintang muda kita aliando syarief telah menjadi ikon untuk Nevada sampai saat ini, hingga saat ini Nevada telah hadir dan mampu menembus dunia international di banyak negara yang tersebar di seluruh dunia sehingga membuat banyak kalangan menyukai dan membeli produk Nevada agar dapat mengikuti trend mode artis yang menjadi panutan mereka (Merdeka.com, 2016).

Nevada merupakan salah satu brand fashion dianggap dapat mempresentasikan citra diri si pemakai. Brand equity dari suatu produk fashion juga membuat seseorang dikenal melalui kelas sosialnya. Apakah merek fashion yang dikenakan termasuk dalam merek yang terkenal maupun tidak. Merek Nevada yang dimiliki oleh Matahari Department Store adalah salah satu private label brand dari tahun 2001 yang kerap kali mendapatkan penghargaan setiap tahunnya. Nevada muncul sebagai salah satu merek yang dikeluarkan oleh salah satu perusahaan ritel yang menyediakan produk pakaian, Nevada saat ini dijual diberbagai pusat perbelanjaan di Bali, yaitu PT. Matahari Department Store, Mall Bali Galeria, Centro Mall Bali dan di beberapa tempat lainnya. Melihat potensi ini banyak merek terkenal lainnya yang membuka tokonya di Indonesia dan semakin memanjakan sifat konsumerisme masyarakat Indonesia, sebut saja Giordano, Polo Ralph Lauren, Cole, dan beberapa merek lainnya. Pada penjualannya Nevada meraih beberapa penghargaan atas sepak terjangnya dalam dunia binis retail 
A.A. Gede Tresna SP, Pengaruh Brand Equity Dan...

fashion. Salah satunya disebutkan dalam artikel bahwa Matahari Department Store dan Nevada Meraih Marketeers Award sebagai Indonesia's Most Favorite Youth Brand 2014 dari Markplus Inc (http://www.matahari.co.id).

Fenomena yang sering terjadi di Indonesia adalah produsen memasarkan suatu produk tanpa tahu konsep dasar lahirnya produk tersebut. Akhirnya, produk tersebut sekedar dilempar ke pasar tanpa didasari oleh strategi. Akibatnya, ketika pasar kurang menerima produk tersebut, perusahaan kesulitan mencari jalan keluarnya. Untuk membangun hubungan jangka panjang, komunikasi pemasaran juga digunakan untuk membangun dan memperkuat brand equity (Aries and Eirene, 2015).

Terlepas dari itu merek memberikan peran terhadap brand loyalty dalam pemilihan suatu produk. Merek dipersepsikan sebagai produk yang berkualitas, sehingga konsumen dapat memahami sebuah produk hanya melalui eksistensi, fungsi, citra dan mutu. Merek bukanlah sekedar nama, istilah (term), tanda (sign), simbol atau kombinasinya (Abbas and Naser, 2015). Lebih dari itu, merek adalah janji perusahaan secara konsisten memberikan features, benefits dan services kepada para pelanggan (Kotler \& Armstrong, 2012:324). Nilai sebuah perusahaan tidaklah terletak pada jumlah asset-asetnya semata, seperti gedung perkantoran, pabrik, mesin-mesin produksi dan inventaris lainnya, namun termasuk kedalamnya nilai dari ekuitas dari merek tersebut sehingga berperan penting terhadap brand loyalty konsumen (Abbas and Naser, 2015).

Janghyeon et al. (2011) brand equity adalah serangkaian aset dan kewajiban yang terkait dengan sebuah merek, nama, dan symbol yang menambah atau nilai 
yang diberikan sebuah produk atau jasa kepada perusahaan dan atau pelanggan. Brand equity berhubungan dengan nama merek yang dikenal, kesan kualitas, asosiasi merek yang kuat dan aset-aset lainnya seperti paten dan merek dagang (Abul, 2012). Jika pelanggan tidak tertarik pada satu merek dan membeli karena karakteristik produk, harga, kenyamanan, dan dengan sedikit mempedulikan merek, kemungkinan brand equity rendah. Sedangkan jika para pelanggan cenderung membeli suatu merek walaupun dihadapkan pada para pesaing yang menawarkan produk yang lebih unggul, misalnya dalam hal harga dan kepraktisan maka merek tersebut memiliki brand equity yang tinggi (Irwan et al., 2014).

Dalam literatur pemasaran, para peneliti telah menemukan pengaruh consumer satisfaction terhadap brand loyalty. Consumer satisfaction memberikan respon tertentu sebagai hasil evaluasinya terhadap kesenjangan antara harapannya dengan kinerja produk. Menurut Kotler dan Keller (2007:112) (comparison) kepuasan konsumen adalah hasil yang dirasakan oleh pembeli yang mengalami kinerja sebuah perusahaan yang dengan harapannya. Mowen \& Minor (2007:87) menyatakan bahwa consumer satisfaction merupakan keseluruhan sikap yang ditunjukkan konsumen atas barang atau jasa setelah mereka memperoleh dan menggunakanya. Ini merupakan penilaian evaluatif pasca pemilihan yang disebabkan oleh seleksi pembelian khusus dan pengalaman menggunakan barang atau jasa tersebut. Consumer satisfaction merupakan sikap, penilaian respon emotional yang ditunjukkan oleh konsumen setelah proses pembelian sehingga memiliki hubungan pada brand loyalty konsumen (Shahroudi et al., 2015). 
Fenomena persaingan yang ada dalam era globalisasi akan semakin mengarahkan sistem perekonomian Indonesia ke mekanisme pasar yang memposisikan pemasar untuk selalu mengembangkan dan merebut market share (pangsa pasar). Salah satu aset untuk mencapai keadaan tersebut adalah brand atau merek (Andri, 2014). Merek merupakan nama, istilah, tanda, simbol desain, ataupun kombinasinya yang mengidentifikasikan suatu produk atau jasa yang dihasilkan oleh suatu perusahaan (Fanny dan Diah, 2014). Identifikasi tersebut juga berfungsi untuk membedakannya dengan produk yang ditawarkan oleh perusahaan pesaing. Lebih jauh, sebenarnya merek merupakan nilai tangible dan intangible yang terwakili dalam sebuah trademark (merek dagang) yang mampu menciptakan nilai dan pengaruh tersendiri di pasar bila diatur dengan tepat. Saat ini merek sudah menjadi konsep yang kompleks dengan sejumlah ratifikasi teknis dan psikologis (Janghyeon et al., 2011).

Brand loyalty (loyalitas merek) merupakan rasa setia konsumen terhadap merek produk (Anik et al., 2015). Dalam brand loyalty akan dilihat seberapa besar keinginan konsumen untuk menukar suatu merek produk dengan produk lain. Perasaan puas setelah pembelian pada umumnya akan mendorong konsumen untuk melakukan pembelian ulang atau bahkan menjadi kebiasaan membeli (Abdul and Asad-ur, 2014). Dalam jangka panjang, kebiasaan membeli akan mendorong untuk menjadi loyal terhadap merek produk (brand loyalty). Hal ini dapat terjadi karena konsumen mempunyai komitmen tinggi terhadap suatu merek produk tertentu sebagai akibat timbulnya kepuasan masa lalu (Aries and Eirene, 2015). 
Aysel et al. (2012) menyatakan konsep brand equity dan consumer satisfaction digunakan berusaha untuk memaksimalkan pesan positif dan meminimalkan pesan negatif dari suatu brand loyalty, dengan sasaran menciptakan dan menyokong brand equity sehingga menciptakan consumer satisfaction untuk meningkatkan brand loyalty.

Melalui pemaparan masalah yang telah dijabarkan, didukung dengan karya ilmiah dan teori tujuan dari karya ilmiah ini yang hendak dicapai 1) Bagaimana pengaruh brand equity terhadap brand loyalty produk Nevada di Kota Denpasar, 2) Bagaimana pengaruh consumer satisfaction terhadap brand loyalty produk Nevada di Kota Denpasar.

Asosiasi Pemasar Amerika (Kotler dan Amstrong, 2012:129) mendefinisikan merek sebagai nama, istilah, tanda, simbol, atau rancangan, atau kombinasi dari semuanya, yang dimaksudkan untuk mengidentifikasikan barang atau jasa atau kelompok penjualan dan untuk mendiferensiasikannya dari barang dan jasa pesaing. Menurut Undang-Undang Merek No. 15 Tahun 2001 pasal 1 ayat 1 merek merupakan tanda yang berupa gambar, nama, kata, huruf-huruf, angka-angka, susunan warna, atau kombinasi dari unsur-unsur tersebut yang memiliki daya pembeda dan digunakan dalam kegiatan perdagangan barang dan jasa.

Memiliki merek yang kuat merupakan aspek vital bagi perusahaan. Sejumlah studi menemukan dampak positif dari memiliki merek kuat (Tjiptono, 2011): efek berkaitan dengan produk, efek berkaitan dengan harga, Efek berkaitan dengan pemasaran, Efek berkaitan dengan distribusi. 
Loyalitas merupakan hasil dari pembelajaran konsumen pada suatu entitas tertentu (merek, produk, jasa, atau toko) yang dapat memuaskan kebutuhannya. (Kotler dan Kevin, 2008:68). Kesetiaan merek (brand loyalty) merupakan suatu konsep yang sangat penting dalam strategi pemasaran karena memberikan banyak manfaat bagi perusahaan termasuk pembelian berulang dan dapat mengurangi biaya pemasaran (Fouzia and Salma, 2015). Loyalitas dapat diartikan sebagai suatu komitmen yang mendalam untuk melakukan pembelian ulang produk atau jasa yang menjadi preferensinya secara konsisten pada masa yang akan datang dengan cara membeli ulang merek yang sama meskipun ada pengaruh situasional dan usaha pemasaran yang dapat menimbulkan peralihan perilaku (Aries and Eirene, 2015).

Perusahaan yang mempunyai basis pelanggan yang mempunyai loyalitas merek yang tinggi dapat mengurangi biaya pemasaran perusahaan karena biaya untuk mempertahankan pelanggan jauh lebih murah dibandingkan dengan mendapatkan pelanggan baru (Jasmina and Elvedina, 2014). Loyalitas merek yang tinggi dapat meningkatkan perdagangan. Dan dapat menarik minat pelanggan baru karena mereka memiliki keyakinan bahwa membeli produk bermerek minimal dapat mengurangi risiko. Keuntungan lain yang didapat dari loyalitas merek adalah perusahaan dapat lebih cepat untuk merespons gerakan pesaing (Hayan et al., 2015).

Faktor-faktor yang mempengaruhi brand loyalty

Menurut Kotler dan Keller (2007:37) menyebutkan faktor-faktor yang berpengaruh terhadap brand loyalty adalah sebagai berkut Nilai (Harga dan 
Kualitas), Citra (Baik dari kepribadian dan reputasi dari merek tersebut), Kenyamanan dan kemudahan untuk mendapatkan merek, Kepuasan yang dirasakan oleh konsumen, Pelayanan, Garansi dan jaminan yang diberikan oleh merek.

\section{Brand Equity}

Kotler dan Keller (2007:11) ekuitas merek adalah nilai tambah yang diberikan pada produk dan jasa. Nilai ini bisa dicerminkan dalam cara konsumen berfikir, merasa, dan bertindak terhadap merek, harga, pangsa pasar, dan profitabilitas yang dimiliki perusahaan. Dalam model Aaker, Brand Equity diformulasikan dari sudut pandang manajerial dan strategi korporat, dengan landasan utamanya adalah perilaku konsumen (Abdullah, 2014). Aaker menjabarkan aset merek yang berkontribusi pada penciptaan brand equity dalam tiga dimensi yaitu Brand awareness adalah kesanggupan seorang calon pembeli untuk mengenali, mengingat kembali suatu merek sebagai bagian dari suatu kategori merek tertentu, Brand Associations menurut (Aaker, 1997:160) menulis bahwa asosiasi merek adalah segala hal yang berkaitan dengan ingatan mengenai sebuah merek dan Brand Perceived quality dapat didefinisikan sebagai persepsi pelanggan terhadap keseluruhan kualitas atau keunggulan suatu produk atau jasa layanan berkaitan dengan apa yang diharapkan pelanggan dan perceived quality bersifat obyektif karena ditentukan oleh pelanggan.

\section{Kepuasan Pelanggan (Customer Satisfaction)}

Kotler dan Armstrong (2012:70) kepuasan pelanggan adalah suatu tingkatan dimana perkiraan kinerja produk sesuai dengan harapan pembeli. Sedangkan kepuasan pelanggan menurut Zeithaml, Parasuraman dan Malhotra (2002:104) adalah, "Customer's evaluation of a product or service in terms of whether that 
product or service has met the customer's needs and expectations". Dimana menurutnya kepuasan pelanggan adalah penilaian pelanggan atas produk ataupun jasa dalam hal menilai apakah produk atau jasa tersebut telah memenuhi kebutuhan dan ekspektasi pelanggan.

Dutka (2008:199) menyatakan bahwa penilaian kepuasan pelanggan dapat diukur dengan menggunakan tiga atribut kepuasan pelanggan. Atribut-atribut tersebut adalah. Attributes related to product, Produk merupakan apa saja baik yang berwujud maupun yang tidak berwujud yang didalamnya sudah termasuk warna, kemasan, prestise pabrik atau pengecer, dan pelayan yang diberikan yang dapat ditawarkan ke dalam pasar untuk diperhatikan, dimiliki, digunakan, atau dikonsumsi sehingga dapat memuaskan keinginan dan kebutuhan. Attributes related to service, Atribut pelayanan merupakan atribut kepuasan pelanggan yang berkaitan dengan pemberian pelayanan pasca pembelian. Ini karena konsumen akan melakukan evaluasi pasca akuisisi. Tahap pasca akuisisi dimulai setelah pelanggan membuat pilihan dan mulai mengkonsumsi produk yang dipilihnya. Attributes related to purchase, Didalam memutuskan suatu pembelian maka konsumen akan dipengaruhi oleh rangsangan pemasaran dan kondisi lain yang tidak dapat dikendalikan oleh perusahaan.

Menurut Kotler and Armstrong (2012: 37-40) faktor-faktor penentu kepuasan pelanggan terbagi atas lima bagian Product Quality, Konsumen akan merasa puas setelah membeli atau menggunakan produk yang telah dibelinya ternyata kualitas produk sangat baik. Price, Untuk konsumen yang sensitif, biasanya harga yang murah adalah sumber kepuasan yang penting karena mereka akan mendapatkan nilai uang yang tinggi, komponen harga ini relatif tidak penting bagi mereka yang tidak sensitif terhadap harga. Service Quality, Untuk memuaskan pelanggan, suatu perusahaan 
hendaknya terlebih dahulu harus dapat memuaskan karyawan agar produk yang dihasilkan tidak rusak kualitasnya dan pelayanan kepada pelanggan dapat diberikan lebih baik lagi, jika karyawan merasa puas akan lebih mudah bagi mereka untuk menerapkan kepada pelanggan bagaimana rasa puas itu. Emotional Factor, Faktor ini relatif penting karena kepuasan pelanggan timbul pada saat ia sedang mengkonsumsi produk tertentu, hal ini disebabkan karena merek produk tersebut sudah tercipta dengan baik, baik dari segi kualitas, harga yang tidak murah karena harga yang mahal identik dengan kualitas produk yang tinggi dan sebaiknya serta pelayanan yang diberikan (Ria dan Gatot, 2014). Easiness, Konsumen akan semakin puas apabila tempat mudah dicapai dan juga nyaman Dengan mengetahui kelima faktor ini, tentu tidak cukup bagi perusahaan untuk merancang strategi dan program peningkatan kepuasan konsumen.

Abbas and Naser (2015) menemukan brand equity atau ekuitas merek yang diterapkan mampu memberikan dampak positif dan signifikan dalam menciptakan brand loyalty pelanggan. Ini pun diungkapkan oleh Aries dan Eirene (2015) penerapan brand equity atau ekuitas merek mampu menciptakan dampak positif signifikan terhadap brand loyalty pelanggan. Hal yang sama di buktikan oleh Mustafa (2010) brand equity memberikan pengaruh positif terhadap brand loyalty pada pelanggan. Berdasarkan pemahaman tersebut dapat dirumuskan hipotesis pertama sebagai berikut.

$\mathrm{H}_{1}$ : brand equity mempengaruhi brand loyalty secara positif.

Customer satisfaction atau kepuasan pelanggan memberikan pengaruh secara positif dan signifikan pada brand loyalty yang dimiliki konsumen (Aries dan Eirene, 2015). Janghyeon et al. (2011) membuktikan hal yang sama customer satisfaction akan mewujudkan brand loyalty yang dimiliki konsumen akan suatu 
produk. Shahroudi and Naimi (2015) membuktikan hal yang sama brand loyalty sebagai loyalty intention konsumen secara positif dipengaruhi oleh customer satisfaction. Berdasarkan hasil penelitian tersebut, diajukan hipotesis ke empat sebagai berikut.

$\mathrm{H}_{2}$ : customer satisfaction mempengaruhi brand loyalty secara positif.

Berdasarkan penelusuran kajian pustaka dan hasil-hasil penelitian terdahulu maka model penelitian dapat digambarkan seperti berikut.

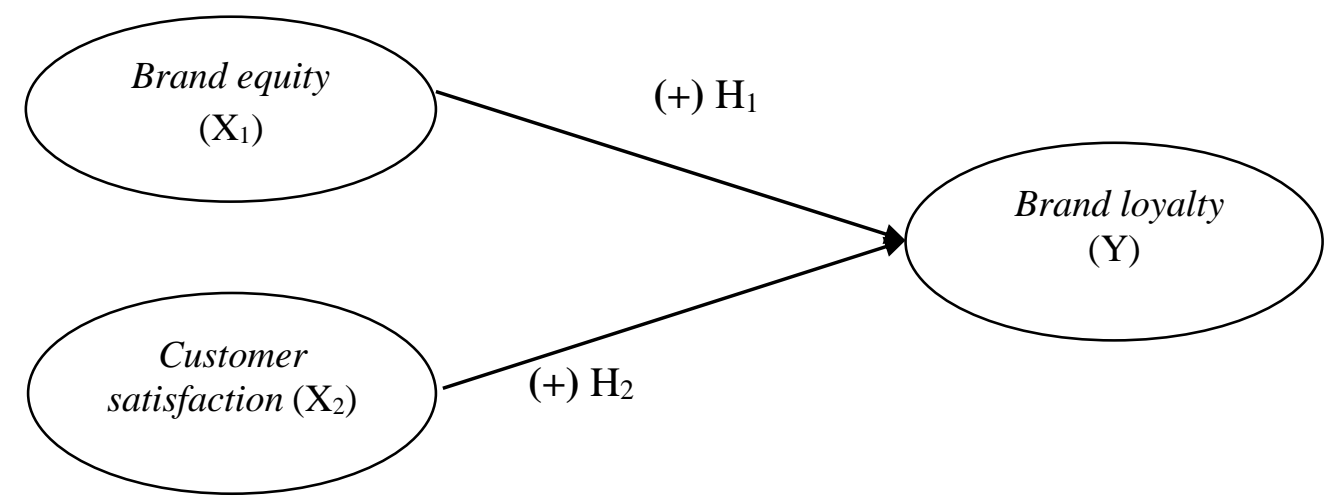

\section{Gambar 1 Kerangka Konseptual}

sumber: Data Diolah, 2017

\section{METODE PENELITIAN}

Karya ilmiah ini digolongkan pada penelitian asosiatif. Penelitian asosiatif merupakan penelitian yang bertujuan untuk mengetahui pengaruh ataupun juga hubungan antara dua variabel atau lebih (Sugiyono, 2010:56). Lokasi penelitian dilakukan di Kota Denpasar. Lokasi ini dipilih karena Kota Denpasar merupakan pusat kota dengan pertumbuhan sektor ekonomi masyarakat sangat cepat, jumlah penduduk yang padat dan populasi yang cukup tinggi. Selain itu secara teknis, Kota Denpasar memenuhi kategori yang dinilai efektif dan efisien dalam menyelenggarakan penelitian yang relevan, mengingat dari segi pendapatan 
penduduk yang berdomisili dan bekerja di Denpasar memiliki rata-rata pendapatan UMR tertinggi dibandingkan dengan di wilayah lainnya (BPS.Kota Denpasar, 2016).

Obyek penelitian adalah pengaruh brand equity dan customer satisfaction pada brand loyalty pada produk Nevada di Kota Denpasar. Subyek penelitian ini adalah brand loyalty konsumen. Variabel bebas adalah brand equity $\left(\mathrm{X}_{1}\right)$ dan customer satisfaction $\left(\mathrm{X}_{2}\right)$, variabel terikat adalah brand loyalty $(\mathrm{Y})$. Jenis data dan sumber data yang digunakan seperti data kualitatif dilihat dari gambaran umum tempat penelitian dan sejarah singkat perusahaan. Data kuantitatif seperti data tanggapan responden terhadap kuisioner yang diberikan, jumlah sampel responden. Sumber primer seperti pendapat pelanggan yang akan dianalisis berdasarkan daftar pertanyaan yang diajukan oleh peneliti dalam kuisioner yang dibagikan. Sumber sekunder seperti sejarah perusahaan, struktur organisasi, landasan teoritis, dan buku-buku yang berkaitan dengan pembahasan masalah ini atau dari informasi-informasi lain yang relevan dengan pembahasan yang dibahas.

Jumlah sampel dalam hal ini konsumen yang memiliki sikap consumer satisfaction terhadap produk Nevada di Kota Denpasar sebanyak 140 orang di klasifikasikan berdasarkan metode teknik non probability sampling (Sugiyono, 2010:118).

Data yang dikumpulkan dalam penelitian ini menggunakan metode kuesioner melalui pertanyaan terstruktur yang telah dipersiapkan sebelumnya dan diberikan kepada responden yang telah dipilih dan dipergunakan untuk memperoleh data konsumen atau responden. Studi Pustaka adalah metode 
pengumpulan data sekunder yang bersumber pada buku, literatur, jurnal-jurnal, referensi yang terkait dengan penelitian yang sedang dilakukan.

Pengujian Instrumen Penelitian

Sebuah instrumen dikatakan valid jika mampu mengukur apa yang seharusnya diukur, dan dapat mengungkap data dari variabel yang diteliti secara tepat. Tinggi rendahnya validitas instrumen menunjukkan sejauh mana data yang terkumpul tidak meyimpang dari gambaran tentang variabel yang dimaksud, yang dianggap memenuhi syarat adalah jika $r>0,3$ dengan signifikansi $<0,05$ ”.

Umar (2007:194) bahwa reliabilitas adalah suatu angka indeks yang menunjukan kosistensi suatu alat ukur dalam mengukur gejala yang sama. Uji reliabilitas mampu menunjukan sejauh mana instrument dapat dipercaya dan diharapkan. Nilai suatu instrumen dikatakan reliabel bila nilai Alpha Cronbach $\geq$ 0,6 .

Data diuji menggunakan analisis regresi linier berganda, untuk mengetahui ketergantungan suatu variabel terikat dengan satu atau lebih variabel bebas. Dalam analisis, peneliti dibantu dengan program computer Statitical Pacage of Social Science (SPSS) versi 15.0 for Windows. Adapun bentuk umum dari persamaan regresi linier berganda menurut (Suyana, 2008:93) sebagai berikut. $\mathrm{Y}=\alpha+\beta_{1} X_{1}+\beta_{2} X_{2}+\mu i$

Dimana :

$$
\begin{array}{ll}
\mathrm{Y} & =\text { Brand Loyalty } \\
\mathrm{X}_{1} & =\text { Brand Equity } \\
\mathrm{X}_{2} & =\text { Consumer satisfaction } \\
\alpha & =\text { Konstanta } \\
\beta_{1-} \beta_{2} & =\text { Koefisien regresi dari } \mathrm{X}_{1}-\mathrm{X}_{2}
\end{array}
$$


$\mu i \quad=$ Variabel pengganggu (residual error)

Uji normalitas bertujuan untuk menguji apakah suatu data berdistribusi normal atau tidak. Pada prinsipnya normalitas dapat dideteksi dengan melihat penyebaran data (titik) pada sumbu diagonal dari grafik atau dengan melihat histogram dari residualnya (Ghozali:2006). Uji Multikolonieritas bertujuan untuk menguji apakah dalam model regresi ditemukan adanya kolerasi antara variabelvariabel bebas. Jika terjadi kolerasi maka dinamakan terjadi problem multikolonieritas. Model regresi yang baik seharusnya tidak terjadi kolerasi antara variabel-variabel bebas (Umar, 2007:198).

Uji heteroskedastisitas menurut (Ghozali, 2006:105) tujuan dari asumsi ini adalah menguji apakah dalam model regresi terjadi ketidaksamaan varians dari residual satu ke pengamatan yang lain tetap maka disebut homokedasitas jika berbeda disebut heteroskedastisitas.

Untuk menguji model regresi pengaruh variabel bebas brand equity $\left(\mathrm{X}_{1}\right)$ dan consumer satisfaction $\left(\mathrm{X}_{2}\right)$ secara serempak terhadap variabel terikat brand loyalty (Y). Uji hipotesis atau t-test bertujuan untuk menguji signifikansi pengaruh variabel brand equity $\left(\mathrm{X}_{1}\right)$ dan consumer satisfaction $\left(\mathrm{X}_{2}\right)$ secara parsial terhadap variabel terikat brand loyalty $(\mathrm{Y})$.

\section{HASIL DAN PEMBAHASAN}

Hasil uji validitas masih-masing indikator variabel memiliki nilai person correlation lebih besar dari 0,30, yang mengungkapan data dari variabel yang 
diteliti secara tepat layak untuk dipergunakan dalam penelitian ini dapat dilihat pada Tabel 1.

Tabel 1.

Hasil Uji Validitas

\begin{tabular}{ccccc}
\hline No & Variabel & Indikator & Korelasi & Keterangan \\
\hline 1 & Brand Equity $\left(\mathrm{X}_{1}\right)$ & $\mathrm{X} 1.1$ & 0,762 & Valid \\
& & $\mathrm{X} 1.2$ & 0,810 & Valid \\
\multirow{2}{*}{2} & \multirow{2}{*}{ Customer Satisfaction $\left(\mathrm{X}_{2}\right)$} & $\mathrm{X} 1.3$ & 0,800 & Valid \\
& & $\mathrm{X} 1.1$ & 0,798 & Valid \\
& $\mathrm{X} 1.2$ & 0,676 & Valid \\
& & $\mathrm{X} 1.3$ & 0,792 & Valid \\
& & $\mathrm{X} 1.4$ & 0,857 & Valid \\
3 & \multirow{2}{*}{ Brand Loyalty $(\mathrm{Y})$} & $\mathrm{X} 1.5$ & 0,792 & Valid \\
& & $\mathrm{Y} .1$ & 0,874 & Valid \\
& & $\mathrm{Y} .2$ & 0,848 & Valid \\
& & $\mathrm{Y} .3$ & 0,728 & Valid \\
& & $\mathrm{Y} .4$ & 0,908 & Valid \\
& & $\mathrm{Y} .5$ & 0,863 & Valid \\
& & $\mathrm{Y} .6$ & 0,662 & Valid \\
\hline
\end{tabular}

Sumber : Data Diolah, 2017

Hasil uji reliabilitas dengan nilai Cronbach's Alpha untuk masing-masing variabel $>0,6$, ini berarti alat ukur tersebut akan memberikan hasil yang konsisten apabila alat ukur tesebut digunakan kembali untuk meneliti obyek yang samayang disajikan pada Tabel 2.

Tabel 2.

Hasil Uji Reliabilitas

\begin{tabular}{clcc}
\hline \multirow{2}{*}{ No } & Variabel & Cronbach's & Keteranga \\
& & Alpha & $\mathrm{n}$ \\
\hline 1 & Brand Equity $\left(\mathrm{X}_{1}\right)$ & 0,693 & Reliabel \\
2 & Customer Satisfaction $\left(\mathrm{X}_{2}\right)$ & 0,833 & Reliabel \\
3 & Brand Loyalty $(\mathrm{Y})$ & 0,899 & Reliabel \\
\hline
\end{tabular}

Sumber : Data Diolah, 2017

Adapun hasil analisis regresi dengan program statitical pacage of social science (SPSS) versi 16.0 for Windows dapat dilihat pada Tabel 3 berikut. 
Tabel 3.

Rangkuman Hasil Analisis Regresi Linear Berganda

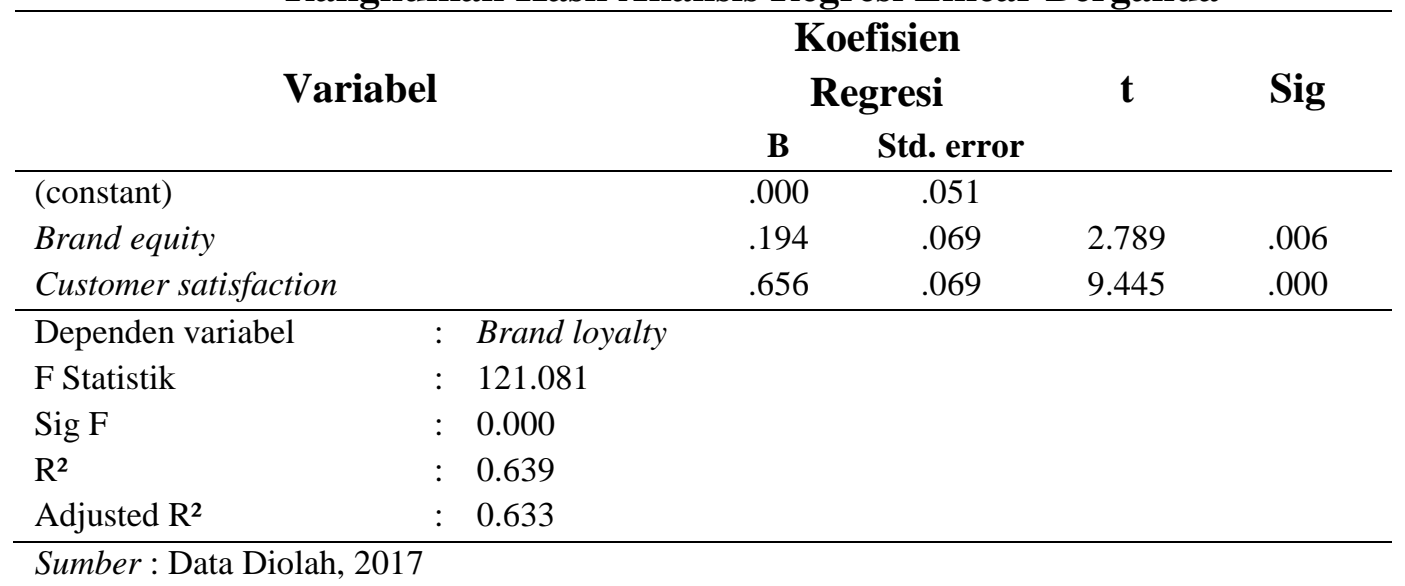

Berdasarkan Tabel 3 dapat ditulis persamaan regresi linear berganda sebagai berikut.

$Y=0,000+0,194 X_{1}+0,656 X_{2}$

Nilai konstanta sebesar 0,000 menunjukan bahwa bila brand equity $\left(\mathrm{X}_{1}\right)$, customer satisfaction $\left(\mathrm{X}_{2}\right)$ sama dengan nol, maka nilai brand loyalty $(\mathrm{Y})$ konstant sebesar 0,000 satuan. Nilai koefisien $\beta_{1}=0,194$ berarti menunjukkan bila brand equity $\left(\mathrm{X}_{1}\right)$ bertambah 1 satuan, maka nilai dari brand loyalty (Y) akan mengalami kenaikan sebesar 0,194 satuan dengan asumsi variabel bebas lainnya konstan.Nilai koefisien $\beta_{2}=0,656$ berarti menunjukkan bila customer satisfaction $\left(\mathrm{X}_{2}\right)$ bertambah 1 satuan, maka nilai dari brand loyalty $(\mathrm{Y})$ akan mengalami kenaikan sebesar 0,656 satuan dengan asumsi variabel bebas lainnya konstan.

Menguji Ketepatan Model Regresi (f-tes)

Pengujian ini dilakukan untuk mengetahui tingkat signifikansi pengaruh variabel bebas secara bersama (simultan) terhadap variabel terikat. Uji $F$

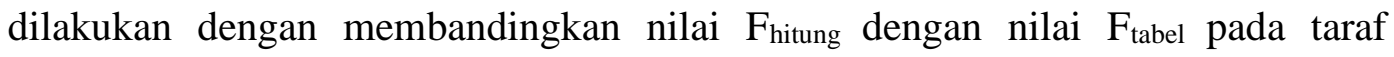
signifikansi 0,05. Berdasarkan hasil perhitungan regresi linear berganda yang 
dirangkum pada lampiran 6 dapat diketahui bahwa $F_{\text {hitung }}=121,081$ dan nilai $F_{\text {tabel }}$ dengan tingkat keyakinan $95 \%$ dan $\alpha=0,05$; df $=(k-1):(n-k)=(2: 137)$ adalah sebesar 3,07 (lampiran 7). Oleh karena $F_{\text {hitung }}(121,081)$ lebih besar dari $F_{\text {tabel }}$ $(3,07)$ dengan nilai signifikansi $0,000<0,05$ maka dapat disimpulkan brand equity, customer satisfaction berpengaruh signifikan secara simultan terhadap brand loyalty. Hal ini berarti model dapat digunakan untuk analisa lebih lanjut atau dengan kata lain model dapat digunakan untuk mempresentasikan karena hasil goodness of fitnya baik. Selain itu dari nilai koefisien determinasi $\mathrm{R}^{2}$ juga memiliki nilai yang cukup tinggi yaitu 0,639 hal ini menandakan bahwa sebesar 63,9 persen variasi brand loyalty dapat dijelaskan oleh brand equity, customer satisfaction sedangkan sisanya 36,1 persen dipengaruhi oleh faktor-faktor lain yang tidak diteliti.

Uji normalitas akan ditampilkan pada Tabel 4 hasil yang didapatkan dengan menggunakan uji Kolmogorov-Smirnov dengan signifikansi lebih besar dari 0,05 yaitu 0,281 maka dapat disimpulkan bahwa model regresi terdistribusi secara normal.

Tabel 4.

Hasil Uji Kolmogorov-Smirnov

\begin{tabular}{llr}
\hline & & $\begin{array}{r}\text { Unstandar } \\
\text { dized Residual }\end{array}$ \\
$\mathrm{N}$ & Mean & 140 \\
Normal Parameters(a,b) & Std, Deviation & .0000000 \\
& Absolute & .60110135 \\
Most Extreme Differences & Positive & .084 \\
& Negative & .043 \\
& & -.084 \\
Kolmogorov-Smirnov Z & & .990 \\
Asymp. Sig. (2-tailed) & & .281 \\
\hline Sumber : Data Diolah, 2017 & &
\end{tabular}


Hasil pengujian multikolinearitas dapat diperoleh hasil sebagai berikut pada Tabel 5.

Tabel 5.

Hasil Uji Multikolinearitas

\begin{tabular}{clcc}
\hline & & \multirow{2}{*}{ Model } & \multicolumn{2}{c}{ Collinearity Statistik } \\
No & & Tolerance & VIF \\
\hline 1 & Brand equity & 0.547 & 1.828 \\
2 & Customer satisfaction & 0.547 & 1.828 \\
\hline
\end{tabular}

Tabel 5. Menunjukkan nilai VIF (Varian Inflatation Factor) tidak lebih dari 10 dan mempunyai angka tolerance tidak kurang dari 0,1, maka ini berarti dalam model regresi tidak terjadi multikolinearitas.

Tabel 6.

Hasil Uji Heteroskedastisitas (Uji Glejser)

\begin{tabular}{|c|c|c|c|c|c|c|}
\hline \multirow{3}{*}{ Model } & & \multicolumn{2}{|c|}{$\begin{array}{l}\text { Unstandardized } \\
\text { Coefficients }\end{array}$} & \multirow[t]{2}{*}{$\begin{array}{l}\text { Standardized } \\
\text { Coefficients }\end{array}$} & \multirow{3}{*}{$\mathbf{t}$} & \multirow{3}{*}{ Sig. } \\
\hline & & & Std. & & & \\
\hline & & B & Error & Beta & & \\
\hline 1 & (Constant) & .463 & .032 & & 14.286 & .000 \\
\hline 2 & Brand equity & -.011 & .044 & .029 & -.254 & .800 \\
\hline 3 & Customer satisfaction & .028 & .044 & .074 & .638 & .525 \\
\hline
\end{tabular}

Berdasarkan tabel 6 diatas dapat dilihat bahwa hampir semua variabel memiliki nilai sig > 0,05 ini berarti pada model regresi tidak terjadi gejala heteroskedasitisitas.

Pengaruh tiap-tiap variabel bebas dalam model ini digunakan untuk mengetahui pengaruh variabel bebas, yaitu brand equity $\left(\mathrm{X}_{1}\right)$, customer satisfaction $\left(\mathrm{X}_{2}\right)$ secara parsial terhadap brand loyalty $(\mathrm{Y})$. Hasil analisis uji t dapat dilihat pada Tabel 7 . 
Tabel 7.

Hasil Analisis Uji t-test

\begin{tabular}{ccccc}
\hline Variabel & thitung & ttabel & Hasil Uji t & Hasil Hipotesis \\
\hline $\mathrm{X}_{1}$ & 2,789 & 1,658 & $(2,975)>(1,658)$ & $\mathrm{H}_{0}$ ditolak \\
$\mathrm{X}_{2}$ & 9,445 & 1,658 & $(4,700)>(1,658)$ & $\mathrm{H}_{0}$ ditolak \\
\hline
\end{tabular}

Sumber : Data Diolah, 2017

Hipotesis ini menyatakan bahwa kompensasi berpengaruh terhadap prestasi kerja karyawan. Brand equity $\left(\mathrm{X}_{1}\right)$ memiliki nilai $\mathrm{t}_{\text {hitung }}=2,789$ lebih besar dari $\mathrm{t}_{\text {tabel }}=1,658$ maka $\mathrm{H}_{0}$ ditolak, ini berarti brand equity berpengaruh positif terhadap brand loyalty produk Nevada di Kota Denpasar. Positif, erat, dan signifikan dalam arti kedua variabel antara brand equity dengan brand loyalty saling berpengaruh besar/erat satu sama lain dengan didasarkan pada perhitungan olah data statistik yang signifikan.

Hipotesis ini menyatakan bahwa customer satisfaction berpengaruh terhadap brand loyalty. Customer satisfaction $\left(\mathrm{X}_{2}\right)$ memiliki nilai $\mathrm{t}_{\text {hitung }}=9,445$ lebih besar dari $\mathrm{t}_{\text {tabel}}=1,658$ maka $\mathrm{H}_{0}$ ditolak, ini berarti customer satisfaction berpengaruh signifikan positif brand loyalty produk Nevada di Kota Denpasar. Positif, erat, dan signifikan dalam arti kedua variabel antara customer satisfaction dengan brand loyalty saling berpengaruh besar/erat satu sama lain dengan didasarkan pada perhitungan olah data statistik yang signifikan.

Pembahasan Hasil Penelitian

Hasil analisis data brand equity memberikan pengaruh positif terhadap niat brand loyalty konsumen pada produk Nevada di Kota Denpasar, terlihat perasaan konsumen terhadap brand equity produk Nevada memberikan pengaruh positif terhadap brand loyalty konsumen untuk membeli produk Nevada di Kota 
Denpasar. Hasil penelitian ini searah dengan pernyataan Abbas and Naser (2015) menemukan brand equity atau ekuitas merek yang diterapkan mampu memberikan dampak positif dan signifikan dalam menciptakan brand loyalty pelanggan. Ini pun diungkapkan oleh Aries dan Eirene (2015) penerapan brand equity atau ekuitas merek mampu menciptakan dampak positif signifikan terhadap brand loyalty pelanggan. Hal yang sama di buktikan oleh Mustafa (2010) brand equity memberikan pengaruh positif terhadap brand loyalty pada pelanggan.

Berdasarkan hasil analisis data diketahui bahwa customer satisfaction terhadap brand loyalty konsumen pada produk Nevada di Kota Denpasar berpengaruh signifikan positif. Hal ini mengandung arti bahwa semakin baik customer satisfaction yang dirasakan konsumen di dalam membeli produk Nevada berakibat positif pada brand loyalty konsumen untuk membeli produk Nevada di Kota Denpasar. Hasil penelitian ini mendukung pernyataan Janghyeon et al. (2011) membuktikan hal yang sama customer satisfaction akan mewujudkan brand loyalty yang dimiliki konsumen akan suatu produk. Customer satisfaction atau kepuasan pelanggan memberikan pengaruh secara positif dan signifikan pada brand loyalty yang dimiliki konsumen (Aries dan Eirene, 2015). Shahroudi and Naimi (2015) membuktikan hal yang sama brand loyalty sebagai loyalty intention konsumen secara positif dipengaruhi oleh customer satisfaction.

\section{SIMPULAN DAN SARAN}

Berdasarkan pada pembahasan pada bab-bab sebelumnya, maka adapun halhal yang dapat disimpulkan yaitu, brand equity berpengaruh positif dan signifikan 
A.A. Gede Tresna SP, Pengaruh Brand Equity Dan...

terhadap brand loyalty produk Nevada di Kota Denpasar. Customer satisfaction berpengaruh positif dan signifikan terhadap brand loyalty produk Nevada di Kota Denpasar.

Berdasarkan simpulan, saran-saran yang dapat diberikan kepada pihak Matahari Department Store sebagai distributor dan penjual produk Nevada di Kota Denpasar sedapat mungkin mempertahankan brand equity produk Nevada sesuai dengan yang diingikan konsumen. Maka dari itu produsen produk merek Nevada hendaknya memperhatikan posisi dan pandangan konsumen akan pentingnya suatu merek bagi konsumen dengan selalu menjaga kualitas produk, harga produk, sehingga mampu meningkatkan loyalitas konsumen. Matahari Department Store sebagai distributor dan penjual pakaian Nevada di Kota Denpasar harus memperhatikan customer satisfaction yang dirasakan konsumen dalam membeli pakaian Nevada di Kota Denpasar, maka dari itu produsen Nevada agar meningkatkan kualitas layanan yang diberikan selama ini kepada konsumen, karena kualitas pelayanan sebagai kunci yang sangat menentukan customer satisfaction sehingga meningkatkan loyalitas konsumen membeli produk Nevada di Kota Denpasar.

\section{REFERENSI}

Abbas Monavvarian., and Naser Asgari, 2015. Studying The Effects Of Brand Equity on The Consumers Responses In The Service Markets. International Journal of Economics, Commerce and Management. 3(3): 118.

Abul Hasan Asy'ari, 2012. Pengaruh Value, Trust, Brand Equity dan Brand Image Terhadap Behavioral Loyalty Konsumen Sepeda Motor Honda di Banjarmasin. Jurnal Ekonomi Manajemen. 6(1): 1-16. 
Abdul Ghafoor Awan., and Asad-ur Rehman. 2014. Impact of customer satisfaction on brand loyalty an empirical analysis of home appliances in Pakistan. British Journal of Marketing Studies. 2(8): 18-32.

Abdullah Awad Alhaddad. 2014. The effect of brand image and brand loyalty on brand equity. International Journal of Business and Management Invention. 3(5): 28-32.

Ali Shirazi., Hanzaleh Zeynvand Lorestani., and Ahmadreza Karimi Mazidi. 2013. Investigating the Effects of Brand Identity on Customer Loyalty from Social Identity Perspective. Iranian Journal of Management Studies (IJMS). 6(2): 153-178.

Andri Helmi Munawar. 2014. Analisis Pengaruh Brand Trust dan Customer Satisfaction Terhadap Loyalitas Pelanggan (Suatu Penelitian Pada Pengguna Kartu Esia PT Bakrie Telecom Tasikmalaya). Jurnal Ekonomi Manajemen. 2(4): 1-14.

Anik Tri Suwarni., Ardianto Nugroho., dan Nurlina Rahman. 2015. Implementasi Strategi Peningkatan Loyalitas Pelanggan Melalui Corporate Brand Equity, Product Atribute dan Service quality Studi Kasus pada perusahaan distribusi bahan baku Bakery dan Pastry untuk wilayah Pemasaran Jakarta dan Bandung. Jurnal MIX. 5(1): 1-16.

Aries Susanty., and Eirene Kenny, 2015. The Relationship between Brand Equity, Customer Satisfaction, and Brand Loyalty on Coffee Shop: Study of Excelso and Starbucks. Journal Asean Marketing. 3(1): 14-27.

Aysel Ercis., Sevtap Unal., F. Burcu Candan., and Hatice Yildirim. 2012. The effect of brand satisfaction, trust and brand commitment on loyalty and repurchase intentions. Journal of International Strategic Management Conference. 5(8): 1-10.

Badan Pusat Statistik. 2015. Denpasar dalam Angka. Berbagai edisi. BPS Provinsi Bali.

Dutka, Alan. 2008. AMA Hand Book for Customer Satisfaction. NTC Business Book,. Lincolnwood, Illinois.

Fanny Fibriyanti Salim., dan Diah Dharmayanti. 2014. Pengaruh Brand Image dan Perceived Quality Terhadap Kepuasan dan Loyalitas Pelanggan Mobil Toyota di Surabaya. Jurnal Manajemen Pemasaran. 2(1): 1-8.

Fouzia Ali., and Salma Muqadas. 2015. The Impact of Brand Equity on Brand Loyalty: The Mediating Role of Customer Satisfaction. Pakistan Journal of Commerce and Social Sciences. 9 (3): 890-915.

Ghozali, Imam, 2006. Aplikasi Analisis Multivariate Dengan Program SPSS. Edisi Kedua.Semarang : Bagian Penerbit Universitas Diponogoro. 
Hayan Dib., and Samaan Al-Msallam. 2015. The Effects of the Determinants of Customer Satisfaction on Brand Loyalty. Journal of Research in Business and Management. 3(3): 1-12.

Herry Widagdo, 2011. Analisis Pengaruh Kualitas Layanan Dan Promosi Terhadap Keputusan Konsumen Membeli Komputer Pada PT. XYZ Palembang. Jurnal Bisnis dan Kewirausahaan. 1(1): 1-10.

Irwan Hartono Alinegoro., Hastuti Naibaho., dan Oliandes Sondakh. 2014. Pengaruh Elemen Ekuitas Merek (Brand Equity) terhadap Keputusan Pembelian Produk Pakaian (X) S.M.L di Surabaya. Jurnal Gema Aktualita. 3(1): h: 32-43.

Janghyeon Nam Kyungnam., Yuksel Ekinci., and Georgina Whyatt, 2011. Brand equity and brand loyalty and Consumer Satisfaction. Journal Annals of Tourism Research. 38(3): 1009-1030.

Jasmina Dlacic., and Elvedina Kezman. 2014. Exploring Relationship Between Brand Equity and Customer Loyalty on Pharmaceutical Market. International Journal Economic and Business Review. 16(2): 121-131.

Kotler, Philip and G. Armstrong. 2012. Principles of Marketing. 14th ed. New Jersey: Prentice Hall.

Kotler, Philip., dan Kevin Lane. 2008. Manajemen Pemasaran. Jilid I. Edisi 12 Jakarta.

,2007, "Manajemen Pemasaran", Cet 2, Edisi 12, Jilid 1, Alih bahasa: Benyamin Molan. Penerbit PT INDEKS.

Mowen, J., dan Minor, M. 2007. Perilaku Konsumen. Jakarta : Erlangga.

Mustafa Karadeniz. 2010. The Importance of Customer Based Strategic Brand Equity Management for Enterprises. Journal of Naval Science and Engineering. 6(2): 117-132.

Rangkas Salsabila Harsa., dan Syahputra, 2014. Pengaruh Brand Equity Game Mario Terhadap Minat Beli Konsumen Nintendo Indonesia pada Konsol Nintendo (Studi pada komunitas Nintendo Indonesia). Jurnal Manajemen Pemasaran. 1(1): 1-12.

Ravie Rahmadhano, 2012. Pengaruh Brand Equity Terhadap Keputusan Pembelian Konsumen Pada Peter Says Denim Di Kota Bandung. Jurnal Manajemen Pemasaran. 1(1): 1-12.

Shahroudi., Kambiz., and Naimi, Seyedeh Safoura. 2015. The Impact of Brand Image on Customer Satisfaction and Loyalty Intention (Case Study: Consumer of Hygiene Products). International Journal of Engineering Innovation \& Research. 3(1): 2277 - 5668. 
E-Jurnal Manajemen Unud, Vol. 7, No. 1, 2018: 307-331

Sugiyono. 2010. Metode Penelitian Kuantitatif Kualitatif dan $R \& D$. Bandung: Alfabeta.

Umar Husein, 2007. Riset Sumber Daya Manusia Dalam Organisasi. Edisi Revisi. Jakarta: PT. Gramedia Pustaka Utama.

Zeithaml, V. A., Parasuraman, A., and Malhotra, A. 2002. Service quality delivery through web sites: a critical review of extant knowledge. Journal of the academy of marketing science, 30(4): 362-375. 